Article

\title{
Risk assessment for potential radiation-induced cancer after lung and bone marrow exposure during interventional cardiology procedures
}

S. JACOB ${ }^{1}$, O. BAR ${ }^{2}$, O. CATELINOIS ${ }^{3}$, C. MACCIA ${ }^{4}$, D. LAURIER ${ }^{1}$, M.-O. BERNIER ${ }^{1}$

(Manuscript received 25 April 2012; accepted 19 September 2012)

ABSTRACT Interventional cardiology procedures (ICPs), while providing important benefits to patients, also contribute to their radiation exposure, in particular for the organs surrounding the heart. This paper addresses the issue of radiation exposure to the lung and bone marrow related to coronary interventions in terms of organ doses for coronary angiography (CA) and percutaneous transluminal coronary angioplasty (PTCA), and risk assessment of potential radiation-induced cancer. Dosimetric information on 2095 ICPs from French patients was collected. The median lung dose for CA alone was $34 \mathrm{mGy}$ for men and $22 \mathrm{mGy}$ for women and the median bone marrow dose was $8 \mathrm{mGy}$ and $4 \mathrm{mGy}$, respectively; doses were slightly higher for $\mathrm{CA}$ and ad hoc PTCA and nearly twice as high for CA and elective PTCA. Based on the French national mortality registry and Biological Effects of Ionising Radiation VII models, spontaneous and radiation-induced lung cancers and leukaemia were estimated. For men and women aged at least 60 years old at the first ICP, excess risk of potentially fatal cancers attributable to radiation ranged from $0.4 \%$ to $4 \%$. This study provides evidence of the potential risk of radiation-induced cancer after an ICP. The limitations of such calculations are due to the difficulty of taking into account patients' possibly shorter life expectancy than in the general population, linked to their comorbidities and coronary disease. Nevertheless, risk estimates can be used to illustrate the beneficial role of optimisation of doses delivered to the patient.

Keywords: interventional cardiology procedures / organ doses / radiation-induced cancer / risk assessment / epidemiology

\section{Introduction}

Interventional cardiology procedures (ICPs) require X-ray: coronary angiography (CA) is performed for the evaluation of coronary artery disease to identify the

\footnotetext{
1 Institut de radioprotection et de sûreté nucléaire, PRP-HOM, SRBE, Laboratory of Epidemiology, 31 avenue de la Division Leclerc, 92260 Fontenay-aux-Roses, France.

2 Clinique Saint Gatien, 8 place de la Cathédrale, 37000 Tours, France.

Institut de Veille Sanitaire, 12 rue du Val d'Osne, 94410 Saint-Maurice, France.

4 Centre d'Assurance de qualité des Applications Technologiques dans le domaine de la Santé, 43 boulevard Maréchal Joffre, 92340 Bourg-La-Reine, France.
} 
exact location and severity of the disease and mainly in order to plan interventional or surgical treatment; coronary angioplasty, also called percutaneous transluminal coronary angioplasty (PTCA), is the procedure used to treat coronary artery disease (involving a balloon possibly combined with a small wire mesh tube called a stent).

The growing use of these ICPs, while providing important benefits to patients, also contributes to their radiation exposure (UNSCEAR, 1993, 2000, 2003; EURATOM, 1997; Scanff et al., 2008). In France, the annual number of patients undergoing either a CA or PTCA is approximately 250000 and 100000 , respectively (Blanchard, 2007). During these procedures, the organs surrounding the heart are exposed to ionising radiation (Pattee et al., 1993; Harrison et al., 1998; Delichas et al., 2003), in particular the lung and bone marrow. It has been shown that patient radiation doses may markedly vary among the ICPs, but also according to patients, operators or X-ray equipment (Bar et al., 2008; Pantos et al., 2009). There is a current debate about whether the widespread use of X-rays could result in an increased incidence of long-term effects, in particular cancers, in this population; it was estimated that on average, in every 100000 patients subjected to ICPs, about 80 patients would develop fatal cancer during the next 40 years (Efstathopoulos et al., 2004). However, little is known about lung and bone marrow doses and associated cancer risk. With the aim of setting up an epidemiological study to examine the excess risk of radiation-induced cancer due to ICPs, we first presented clinical characteristics and 1-year cumulative doses for a sample of 1591 French patients in a previous article (Bernier et al., 2012). In a second step, a specific risk assessment for cancer was carried out.

The purpose of the present paper was twofold: to describe lung and bone marrow doses received during ICPs based on this French sample of patients and corresponding procedures, and to assess potential radiation-induced cancer risks attributable to the ICPs.

\section{Material and methods}

\subsection{Description of procedures}

Among interventional cardiology procedures, three types of procedures exist and were considered in this paper:

1. patients with a $\mathrm{CA}$ alone corresponding to a diagnostic procedure (with no PTCA);

2. patients with a CA and ad hoc PTCA corresponding to a CA diagnostic procedure immediately followed by treatment with a PTCA procedure; 
RISK ASSESSMENT FOR POTENTIAL RADIATION-INDUCED CANCER

3. patients with CA and elective PTCA corresponding to a CA diagnostic procedure followed, a few days later (less than 7 days), by PTCA.

\subsection{Organ doses}

Lung and bone marrow doses were estimated from a French sample of 2095 IC procedures performed in 2005 in Saint Gatien Clinic (Tours, France) and corresponding to 1591 patients having undergone at least one CA alone, and ad hoc or elective PTCA with or without stenting. The methodology for dosimetric evaluation is detailed elsewhere (Bernier et al., 2012). It allowed obtaining lung and bone marrow doses corresponding to a CA alone, CA and ad hoc PTCA, and CA and elective PTCA.

\subsection{Situations considered for patient exposure}

Based on cardiologist experience and observation of the 1591 patients' characteristics included in the database, we quantified the impact of radiation exposure during ICPs for "typical" patients and situations: for men and women, we considered patients aged 60 or 65 years old undergoing either $\mathrm{CA}$ alone, or $\mathrm{CA}$ and ad hoc PTCA, or CA and elective PTCA. Moreover, we estimated the impact of having a CA alone at 60 years old, and CA and $a d$ hoc PTCA, or CA and elective PTCA at 65 years old. Doses considered for calculations of cancer risk were based on those observed in the sample of 1591 patients.

\subsection{Risk estimates}

Evaluation of the association between radiation exposure and cancer occurrence was evaluated by statistical models adapted to radiation epidemiology. The National Academies' Biological Effects of Ionising Radiation 7th report (BEIR VII) provides a framework for estimating age-, sex- and organ-specific cancer risks from radiation exposure, based on risk coefficients representing the lifetime radiation-induced cancer mortality (or incidence) attributable to an exposure to ionising radiation. According to the BEIR VII report, analysing Excess Relative Risk $(E R R=R R($ relative risk $)-1)$, the following models were used:

- ERR models for estimating site-specific lung cancer mortality:

$\operatorname{ERR}(D, s, e, a)=\beta D \exp \left(-0.3 e^{*}\right)(a / 60)^{-1.4}$,

where $s$ is sex, $D$ is the dose to the lung (in Sv), $e$ corresponds to age at exposure, $e^{*}$ is $(e-30) / 10$ for $e<30$ and 0 for $e \geq 30$, and a is attained age, $\beta=0.32$ for men and $\beta=1.40$ for women;

- ERR models for estimating leukaemia mortality:

$\operatorname{ERR}(D, s, e, t)=\beta_{\mathrm{S}}\left(D+0.87 D^{2}\right) \exp \left[-0.4 e^{*}-0.48 \log (t / 25)+0.42 e^{*} \log (t / 25)\right]$, where $s$ is sex, $D$ is the red bone marrow dose, $e$ corresponds to age at exposure, 
$e^{*}$ is $(e-30) / 10$ for $e<30$ and 0 for $e \geq 30$, and $t$ is time since exposure, $\beta=1.1$ for men and $\beta=1.2$ for women.

A latency time between exposure and possible radiation-induced cancer was considered in the risk assessment: 10 years for lung cancer and 5 years for leukaemia (NRC, 2006).

Our estimates were based on French mortality baseline rates (InVS and INSERM, 2003) considering that follow-up was performed until the maximum age of 85 years, this upper limit being justified by possible discrepancies in causes of death in the national registry above this age limit. We first estimated the number of spontaneous fatal cancers that would appear among 100000 men and women from the age of 60 or 65 years old and followed until the age of 85 . Second, in a population of 100000 patients aged 60 or 65 years old, having undergone ICPs according to the 5 situations of exposure presented above, and followed until 85 years old, we estimated the number of radiation-induced fatal cancers attributable to ICP exposure.

\section{Results}

\subsection{Organ doses according to the IC procedures}

Among the 2095 procedures, 52\% were CA alone, 31\% were CA and ad hoc PTCA, and $17 \%$ were CA and elective PTCA.

Regarding lung doses, CA alone, and CA and ad hoc PTCA were in the same range of doses with a median dose of $34 \mathrm{mGy}$ and $36 \mathrm{mGy}$, respectively, for men; and $22 \mathrm{mGy}$ and $28 \mathrm{mGy}$, respectively, for women. However, for CA and elective PTCA, doses were nearly twice as high, with a median dose of $77 \mathrm{mGy}$ and $59 \mathrm{mGy}$ for men and women, respectively (Fig. 1). Bone marrow doses were slightly higher for CA and ad hoc PTCA than for CA alone. Furthermore, the highest doses were observed for CA and elective PTCA (Fig. 2). We noticed a wide range of doses for all types of procedures, and focused on interquartile ranges for the following analysis.

\subsection{Radiation-induced cancer mortality}

Per 100000 patients aged 60 years old, about 6830 men and 1036 women would die of spontaneous lung cancer considering a follow-up until the age of 85 years (Tab. I). These figures were decreased when considering patients aged 65 years old at the beginning of the follow-up. According to the situation of exposure presented in Table I, we observed that the relative risk of radiation-induced fatal lung cancers 

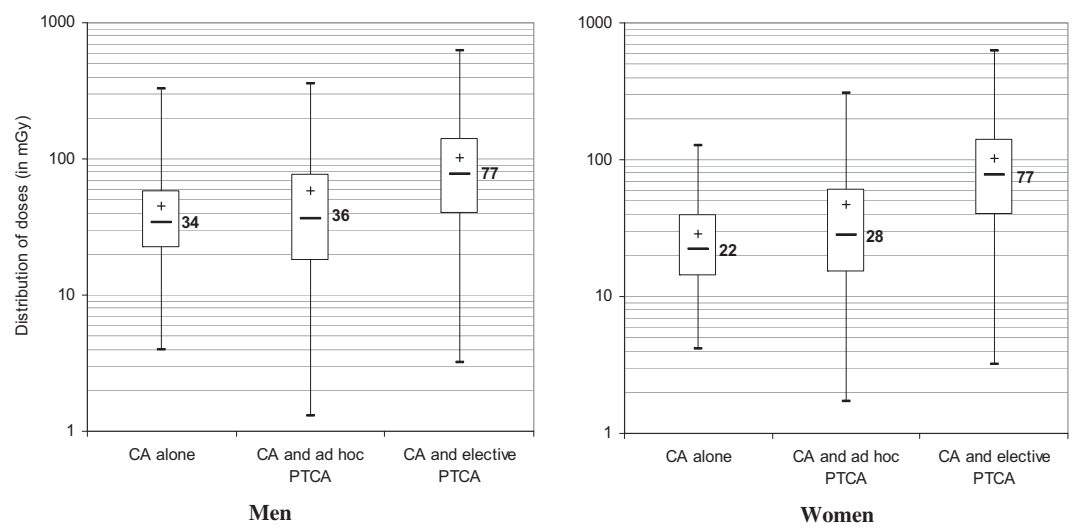

Figure 1 - Description of lung doses in mGy for CA alone, CA and ad hoc PTCA, and CA and elective PTCA. (Box plot description: the bottom and top of the box are the 25th and 75th percentile, the band near the middle of the box is the median, the cross in the box is the mean, upper and lower bands correspond to maximum and minimum.)
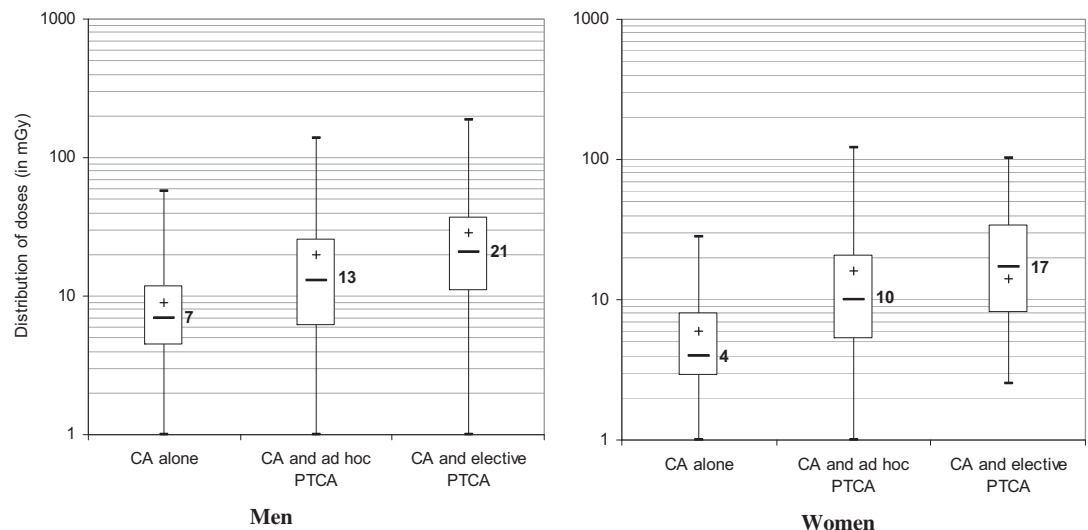

Figure 2 - Description of red bone marrow doses in mGy for CA alone, CA and ad hoc PTCA, and CA and elective PTCA.

ranged from 1.004 to 1.010 for men and 1.013 to 1.041 for women. Additional CA and PTCA at 65 years after a first CA at 60 years multiplied the risk by nearly 3 for women and 2 for men.

Leukaemia mortality was estimated according to the same situations of exposure with corresponding bone marrow doses (Tab. II). With a baseline value of spontaneous cases much lower than for lung cancer (759 and 491 cases/ 100000 for men and women aged 60 years old, respectively), the relative risk of 
TABLE I

Spontaneous and radiation-induced lung cancer mortality (per 100000 individuals).

\begin{tabular}{|c|c|c|c|}
\hline $\begin{array}{l}\text { Gender and age } \\
\text { at exposure }\end{array}$ & $\begin{array}{l}\text { Spontaneous } \\
\text { cases }\end{array}$ & $\begin{array}{l}\text { Exposure: ICP performed } \\
\text { and corresponding lung dose (IQR*) }\end{array}$ & $\begin{array}{l}\text { Potential cases in excess } \\
\text { due to ICP (IQR) and } \\
\text { corresponding Relative } \\
\text { Risk }\end{array}$ \\
\hline $\begin{array}{l}\text { Men aged } \\
60 \text { years at first } \\
\text { ICP }\end{array}$ & 6423 & $\begin{array}{l}\text { CA alone: } 34 \text { mGy (22-59) } \\
\text { CA and ad hoc PTCA: } 36 \text { mGy (18-77) } \\
\text { CA and elective PTCA: } 77 \text { mGy (40-141) }\end{array}$ & $\begin{array}{l}29(19-50)-R R^{* *}=1.004 \\
31(15-65)-R R=1.005 \\
65(34-119)-R R=1.010\end{array}$ \\
\hline $\begin{array}{l}\text { Men aged } 65 \\
\text { years } \\
\text { at first ICP }\end{array}$ & 5673 & $\begin{array}{l}\text { CA alone: } 34 \text { mGy (22-59) } \\
\text { CA and } a d \text { hoc PTCA: } 36 \text { mGy (18-77) } \\
\text { CA and elective PTCA: } 77 \text { mGy (40-141) }\end{array}$ & $\begin{array}{l}22(14-39)-R R=1.004 \\
24(12-50)-R R=1.004 \\
40(26-92)-R R=1.007\end{array}$ \\
\hline $\begin{array}{l}\text { Men aged } 60 \text { years } \\
\text { at first ICP and } \\
65 \text { years at second } \\
\text { ICP }\end{array}$ & 6423 & $\begin{array}{l}\text { CA alone at } 60 \text { years and CA and } a d h o c \\
\text { PTCA at } 65 \text { years } \\
\text { CA alone at } 60 \text { years and CA and elective } \\
\text { PTCA at } 65 \text { years }\end{array}$ & $\begin{array}{l}51(30-98)-R R=1.009 \\
77(25-138)-R R=1.014\end{array}$ \\
\hline $\begin{array}{l}\text { Women aged } \\
60 \text { years at first } \\
\text { ICP }\end{array}$ & 1036 & $\begin{array}{l}\text { CA alone: } 22 \text { mGy (14-40) } \\
\text { CA and ad hoc PTCA: } 28 \text { mGy (15-60) } \\
\text { CA and elective PTCA: } 59 \text { mGy (31-120) }\end{array}$ & $\begin{array}{l}16(10-29)-R R=1.015 \\
20(11-43)-R R=1.019 \\
42(22-86)-R R=1.041\end{array}$ \\
\hline $\begin{array}{l}\text { Women aged } \\
65 \text { years at first } \\
\text { ICP }\end{array}$ & 924 & $\begin{array}{l}\text { CA alone: } 22 \text { mGy (14-40) } \\
\text { CA and ad hoc PTCA: } 28 \text { mGy (15-60) } \\
\text { CA and elective PTCA: } 59 \text { mGy (31-120) }\end{array}$ & $\begin{array}{l}12(8-22)-R R=1.013 \\
15(8-32)-R R=1.016 \\
32(17-65)-R R=1.035\end{array}$ \\
\hline $\begin{array}{l}\text { Women aged } \\
60 \text { years at first } \\
\text { ICP and } 65 \text { years } \\
\text { at second ICP }\end{array}$ & 1036 & $\begin{array}{l}\text { CA alone at } 60 \text { years and CA and } a d h o c \\
\text { PTCA at } 65 \text { years } \\
\text { CA alone at } 60 \text { years and CA and elective } \\
\text { PTCA at } 65 \text { years }\end{array}$ & $\begin{array}{l}30(18-60)-R R=1.029 \\
47(26-92)-R R=1.045\end{array}$ \\
\hline
\end{tabular}

radiation-induced leukaemia deaths was 1.014 for men with CA and ad hocPTCA at 60 years old, and 1.024 for men subjected to CA and elective PTCA. The risk was globally lower for women.

\section{Discussion}

Based on different situations of patients undergoing IC procedures, our results suggest that potential risks of radiation-induced lung cancer mortality and leukaemia mortality exist even if these remain limited based on the organ doses observed in a sample of more than one thousand patients. Moreover, we observed that in the case of treatment with PTCA, elective PTCA induced higher doses and more radiation-induced cases than ad hoc PTCA.

Despite the difficulty of comparing our estimations with other previously published results because of differences in doses and the population considered, we observed risks in the same ranges. Previous risk assessments were often performed taking into account the effective dose (whole body) associatedwith IC procedures. 
TABLE II

Spontaneous and radiation-induced leukaemia mortality (per 100000 individuals).

\begin{tabular}{|c|c|c|c|}
\hline $\begin{array}{l}\text { Gender and age } \\
\text { at exposure }\end{array}$ & $\begin{array}{l}\text { Spontaneous } \\
\text { cases }\end{array}$ & $\begin{array}{l}\text { Exposure: ICP performed and } \\
\text { corresponding lung dose (IQR*) }\end{array}$ & $\begin{array}{l}\text { Potential cases in excess } \\
\text { due to ICP (IQR) and } \\
\text { corresponding Relative } \\
\text { Risk }\end{array}$ \\
\hline $\begin{array}{l}\text { Men aged } 60 \text { years } \\
\text { at first ICP }\end{array}$ & 759 & $\begin{array}{l}\text { CA alone: } 8 \text { mGy (4-12) } \\
\text { CA and ad hoc PTCA: } 13 \text { mGy (6-26) } \\
\text { CA and elective PTCA: } 21 \text { mGy (11-38) }\end{array}$ & $\begin{array}{l}7(3-10)-R R^{* *}=1.009 \\
11(5-23)-R R=1.014 \\
18(9-33)-R R=1.024\end{array}$ \\
\hline $\begin{array}{l}\text { Men aged } 65 \text { years } \\
\text { at first ICP }\end{array}$ & 734 & $\begin{array}{l}\text { CA alone: } 8 \text { mGy (4-12) } \\
\text { CA and } a d \text { hoc PTCA: } 13 \text { mGy (6-26) } \\
\text { CA and elective PTCA: } 21 \text { mGy (11-38) }\end{array}$ & $\begin{array}{l}7(3-10)-R R=1.009 \\
11(5-22)-R R=1.015 \\
17(9-32)-R R=1.023\end{array}$ \\
\hline $\begin{array}{l}\text { Men aged } 60 \text { years at } \\
\text { first ICP and } 65 \text { years } \\
\text { at second ICP }\end{array}$ & 759 & $\begin{array}{l}\text { CA alone at } 60 \text { years and CA and } a d h o c \\
\text { PTCA at } 65 \text { years } \\
\text { CA alone at } 60 \text { years and CA and elective } \\
\text { PTCA at } 65 \text { years }\end{array}$ & $\begin{array}{l}17(8-31)-R R=1.022 \\
23(12-40)-R R=1.030\end{array}$ \\
\hline $\begin{array}{l}\text { Women aged } \\
60 \text { years at first ICP }\end{array}$ & 1036 & $\begin{array}{l}\text { CA alone: } 4 \text { mGy (3-8) } \\
\text { CA and ad hoc PTCA: } 10 \text { mGy (5-21) } \\
\text { CA and elective PTCA: } 17 \text { mGy (8-34) }\end{array}$ & $\begin{array}{l}2(2-4)-R R=1.004 \\
6(3-12)-R R=1.012 \\
9(4-19)-R R=1.018\end{array}$ \\
\hline $\begin{array}{l}\text { Women aged } \\
65 \text { years at first ICP }\end{array}$ & 924 & $\begin{array}{l}\text { CA alone: } 4 \text { mGy (3-8) } \\
\text { CA and } a d \text { hoc PTCA: } 10 \text { mGy (5-21) } \\
\text { CA and elective PTCA: } 17 \text { mGy (8-34) }\end{array}$ & $\begin{array}{l}2(2-4)-R R=1.004 \\
5(3-11)-R R=1.011 \\
9(4-18)-R R=1.019\end{array}$ \\
\hline $\begin{array}{l}\text { Women aged } \\
60 \text { years at first ICP } \\
\text { and } 65 \text { years at } \\
\text { second ICP }\end{array}$ & 1036 & $\begin{array}{l}\text { CA alone at } 60 \text { years and CA and } a d h o c \\
\text { PTCA at } 65 \text { years } \\
\text { CA alone at } 60 \text { years and CA and elective } \\
\text { PTCA at } 65 \text { years }\end{array}$ & $\begin{array}{l}7(4-15)-R R=1.014 \\
11(6-22)-R R=1.022\end{array}$ \\
\hline
\end{tabular}

In a study based on the UK population, it was estimated that about 280 cases of radiation-induced cancer would appear per million examinations due to coronary angiography and considering patients aged between 0 and 75 years (Berrington de Gonzalez and Darby, 2004). In this UK study, the risk of lung cancer attributable to diagnostic X-rays, including CA, was approximately $0.1 \%$ for men and $0.5 \%$ for women (which corresponds to $R R=1.001$ or 1.005 , respectively), and it was $1.4 \%$ and $1.9 \%$, respectively, for leukaemia. We also observed in our calculations that risks were in the same range (from $0.6 \%$ to $6 \%$ approximately considering relative risks) and were higher for women than for men. However, considering that the organs would be differently involved by the primary X-ray beam, it is rather important to take into account organ doses associated with ICPs and to consider specific cancer sites instead of all cancers together when performing a risk assessment. Few studies have focused on such a point. A study showed that for 1000000 patients undergoing an atrial fibrillation procedure, about 1,227 additional lung cancers would appear in women for a lung dose of $81.79 \mathrm{mGy}$, and 2326 men for a lung dose of $122.45 \mathrm{mGy}$ (Lickfett et al., 2004). These results were based on BEIR V report estimates, but, when compared with our study, for a lung 
dose of $77 \mathrm{mGy}$, we found 650 additional cases for 1000000 male patients exposed at 60 years old, which was in the same range.

Three major points of concern have an impact on risk assessment studies: the strong link to dose estimates; the considered age at exposure; and the choice of risk models. To perform the risk assessment, we considered median organ doses and interquartile ranges, thus allowing us to take into account the whole distribution of doses for IC procedures based on a sample of procedures performed in a French centre. These doses are directly dependent on equipment and practitioners, but also the patients included in the study. Nevertheless, we considered that the doses presented here could provide a good indication of the range of doses. A major difficulty of such an evaluation is that the values of organ doses associated with ICPs are not easily available in the literature. However, as presented by Pantos et al. (2009), even for a specific IC procedure, patient doses vary a lot. Organ doses are generally derived from mathematical modelling of the dose-area product (Monte Carlo simulations), inducing another source of approximation. Our median doses were lower (36 mGy to the lung and $13 \mathrm{mGy}$ to the bone marrow for CA and ad hoc PTCA) than previously reported (Efstathopoulos et al., 2004), but considering mean doses, our data were closer to those published by this study and in agreement with the relevant organ doses presented elsewhere (Hall and Brenner, 2008). The wide range of observed doses linked to the procedure complexity, to the patient clinical specificities and to the cardiologists' radioprotection awareness could lead to observing higher risks in some populations of patients. Secondly, we focused on specific situations of exposure. The choice of the scenarios could not completely reflect the patients' exposure due to IC procedures. In some cases, because of the chronic pattern of the disease, more IC procedures than those considered in the scenario would be performed, thus increasing the total received dose as well as the risk of following cancer. On the other hand, our estimations were based on patients aged at least 60 years old at first examination, which, in comparison with younger patients, would have an underestimated risk because of shorter life expectancy and thus shorter time to develop any radiation-induced cancer. Nevertheless, this choice was made to appear coherent and applicable to a wide category of patients. Finally, we used the BEIR VII risk model, which is the most up-to-date, comprehensive and relevant risk estimate model for this kind of analysis.

An important limit in the cancer risk assessment is the lack of consideration of the clinical characteristics of patients in such an evaluation. These individuals can present important comorbidity factors: high body mass index, diabetes, hypertension, hypercholesterolemia, family history of coronary heart disease, history of myocardial infarction, history of coronary bypass. As a consequence of this, risk associated with IC procedures may be lower in patients with such comorbidities, who may not survive long enough to develop a radiation-induced 
cancer as compared with the general population. More precise estimates might be available with a well-designed epidemiological study. A cohort of patients having undergone IC procedures and followed in time with a survey of main outcomes (lung cancer, for example) could, a priori, provide answers. Based on the calculations presented below, it appears that the major weakness of such an epidemiological study, designed to investigate long-term health consequences among diagnosed and treated patients, would be statistical power. Such a cohort at a national level is difficult to launch. With a crude sample size estimation based on ionising radiation attributable risk of cancer of around $2 \%(R R=1.02)$ and a statistical power of $80 \%$, at least 230000 individuals having undergone ICPs and followed for 40 years, or 1200000 individuals followed for 10 years should be included in a cohort. As a consequence, with a risk that remains limited, a small cohort could not allow the demonstration of its existence. In Sweden, for example, a large cohort of 23097 patients having undergone PTCA failed in observing excess risk of leukaemia after a mean follow-up of 5 years (Lambe et al., 2005). Thus, only a wide international participation in such cohorts (Malisan et al., 2008) would allow one to reach sufficient statistical power to test the significance of an excess of radiationinduced cancer after IC procedures. At this first stage, risk assessment has to be considered as a way of examining risks so that they may be better avoided, reduced, or otherwise managed (Wilson and Crouch, 1987).

Even if radiation-induced cancer risk appears relatively limited based on our calculations, the beneficial role of optimisation of doses delivered to the patient and the reduction of this risk, following a process of optimisation, justifies the implementation of the principles of radiation protection. There are several methods that may be applied to optimise the patient exposure during an IC procedure: choosing the correct patient-to-detector distance as well as the appropriate X-ray tube to patient distance, collimating the X-ray beam to the relevant body part to be diagnosed or treated, setting the lowest frame rate possible compatible with the coronary branch to examine and keeping the fluoroscopy time as short as possible (Chambers et al., 2011). As underlined by the International Atomic Energy Agency, optimisation of protection requires that exposure of patients be the minimum necessary to achieve the required diagnosis and therapeutic objective of the interventional procedure. By no means should dose reduction compromise clinical information and outcome, in accordance with the As Low As Reasonably Achievable (ALARA) principle (Picano et al., 2007a, 2007b).

In conclusion, even if it is commonly accepted that the benefits of diagnostic radiation to patients far outweigh the potential risk of developing radiationinduced cancer, this study provides estimates of the potential radiation-induced cancer risk in interventional cardiology. The limitations of such calculations are due to the difficulty of taking into account patients' possibly shorter life prognosis 
than in the general population, partly explained by their comorbidities and coronary disease. With numerical evolution of ICPs, interventions to promote delivered-dose optimisation and "ALARA" requirements may prevent or limit this risk.

\section{There is no conflict of interest.}

\section{REFERENCES}

Bar O., Maccia C., Pages P., Blanchard D. (2008) A multicentre survey of patient exposure to ionising radiation during interventional cardiology procedures in France, EuroIntervention. 3, 593-599.

Bernier M., Jacob S., Maccia C., Bar O., Catelinois O., Blanchard D., Laurier D. (2012) Patient cumulative radiation exposure in interventional cardiology, Radioprotection 47, 93-103.

Berrington de Gonzalez A., Darby S. (2004) Risk of cancer from diagnostic X-rays: estimates for the UK and 14 other countries, Lancet 363, 345-351.

Blanchard D. (2007) Progress in interventional cardiology and stents in France and Europe, Ann. Cardiol. Angéiol. 56, S42-S47.

Chambers R.J., Fetterly K., Holzer R., Lin P.J.P., Blankenship J.C., Balter S., Laskey W. (2011) Radiation safety program for cardiac catheterization laboratory, Cath. Card. Interv. 77, 510514.

Delichas M.G., Psarrakos K., Molyvda-Athanassopoulou E., Giannoglou G., Hatziioannou K., Papanastassiou E. (2003) Radiation doses to patients undergoing coronary angiography and percutaneous transluminal coronary angioplasty, Radiat. Prot. Dosim. 103, 149-154.

Efstathopoulos E.P., Karvouni E., Kottou S., Tzanalaridou E., Korovesis S., Giazitzoglou E., Katritsis D.G. (2004) Patient dosimetry during coronary interventions: a comprehensive analysis, Am. Heart J. 147, 468-475.

EURATOM (1997) Council Directive 97/43, On health protection of individuals against the dangers of ionising radiation in relation to medical exposure, L180/22.

Hall E.J., Brenner D.J. (2008) Cancer risks from diagnostic radiology, The British journal of radiology. 81, 362-378.

Harrison D., Ricciardello M., Collins L. (1998) Evaluation of radiation dose and risk to the patient from coronary angiography, Aust. N. Z. J. Med. 28, 597-603.

InVS and INSERM (2003) Evolution de l'incidence et de la mortalité par cancer en France de 1978 à 2000, Réseau français des registres du cancer.

Lambe M., Hall P., Granath F., Sadr Azodi O., Nillsson T. (2005) Coronary angioplasty and cancer risk: a population-based cohort study in Sweden, Cardiovasc. Intervent. Radiol. 28, 36-38.

Lickfett L., Mahesh M., Vasamreddy C., Bradley D., Jayam V., Eldadah Z., Dickfeld T., Kearney D., Dalal D., Luderitz B., Berger R., Calkins H. (2004) Radiation exposure during catheter ablation of atrial fibrillation, Circulation 110, 3003-3010.

Malisan M.R., Padovani R., Faulkner K., Malone J.F., Vano E., Jankowski J., Kosunen A. (2008) Proposal for a patient database on cardiac interventional exposures for epidemiological studies, Radiat. Prot. Dosim. 129, 96-99.

NRC (2006) National Research Council of the National Academies, Commitee to assess Health Risks from Exposure to Low Levels of Ionizing Radiations; Nuclear and Radiation Studies Board, Division on Earth and Life Studies Health Risks From Exposure to Low Levels of Ionizing Radiations: BEIRVII Phase 2. Washington DC: The National Academies Press. 
Pantos I., Patatoukas G., Katritsis D.G., Efstathopoulos E. (2009) Patient radiation doses in interventional cardiology procedures, Curr. Cardiol. Rev. 5, 1-11.

Pattee P.L., Johns P.C., Chambers R.J. (1993) Radiation risk to patients from percutaneous transluminal coronary angioplasty, J. Am. Coll. Cardiol. 22, 1044-1051.

Picano E., Santoro G., Vano E. (2007a) Sustainability in the cardiac cath lab, Int. J. Cardiovasc. Im. 23, 143-147.

Picano E., Vano E., Semelka R., Regulla D. (2007b) The American College of Radiology white paper on radiation dose in medicine: deep impact on the practice of cardiovascular imaging, Cardiovasc. Ultrasound 5, 37.

Scanff P., Donadieu J., Pirard P., Aubert B. (2008) Population exposure to ionizing radiation from medical examinations in France, Brit. J. Radiol. 81, 204-213.

UNSCEAR (1993) Sources and effects of ionizing radiation. Report to the General Assembly, with scientific annexes.

UNSCEAR (2000) Sources and effects of ionizing radiation, Vol. 2, Annex G: Biological effects at low radiation doses, New-York, United Nations.

UNSCEAR (2006) Effects of ionizing radiation - United Nations Scientific Committee on the Effects of Atomic Radiation. New York, United Nations.

Wilson R., Crouch E.A. (1987) Risk assessment and comparisons: an introduction, Science (New York) 236, 267-270. 